\title{
Survival in hypercalcaemic patients with cancer and co-existing primary hyperparathyroidism
}

\author{
ACJ Hutchesson, NJ Bundred, WA Ratcliffe
}

\begin{abstract}
Summary
Hypercalcaemia associated with malignancy is generally thought to carry a poor prognosis. Of 47 consecutive patients with hypercalcaemia and malignancy, serum parathyroid hormone (PTH) was elevated in seven, consistent with co-existing hyperparathyroidism. Median survival from onset of hypercalcaemia in these seven patients was 817 days; compared to 33 days in the remaining 40 patients with hypercalcaemia of malignancy, in whom PTH was suppressed $(p=0.007)$. Among patients with hypercalcaemia of malignancy, plasma PTH-related protein (PTHrP) concentration showed no correlation with survival $\left(r^{2}=2.1 \%\right)$, but one patient with increased levels of both PTH and PTHrP survived only nine days after the onset of hypercalcaemia. A raised PTH had a positive predictive value of $86 \%$ for survival $>100$ days, and of $71 \%$ for survival $>1$ year. A raised plasma PTHrP predicted death within 100 days with a positive predictive value of $69 \%$.

We conclude that measurement of serum PTH is indicated in patients with hypercalcaemia and malignancy to identify the $15 \%$ with hyperparathyroidism, since this is associated with prolonged survival. In patients with hyperparathyroidism, assay of plasma PTHrP may indicate concurrent hypercalcaemia of malignancy, with an associated poor prognosis.
\end{abstract}

Selly Oak Hospital

Birmingham B29 6JD,

UK

Department of

Clinical Biochemistry

ACJ Hutchesson

Department of

Surgery

NJ Bundred

Wolfson Research

Laboratories, Queen

Elizabeth Hospital,

Birmingham B15 2TH,

UK

WA Ratcliffe

Correspondence to

Dr ACJ Hutchesson,

Department of Clinical

Chemistry, the City Hospital,

Dudley Road, Birmingham

B18 7QH, UK

Accepted 22 August 1994
Keywords: hypercalcaemia, carcinoma, hyper-

\section{Introduction}

Hypercalcaemia is an important complication of malignant disease. ${ }^{1}$ The pathogenesis of hypercalcaemia of malignancy hypercalcaemia of malignancy was initially attributed to ectopic production of parathyroid hormone (PTH), but specific assays for PTH failed to demonstrate tumoral production. More recently, PTH-related protein (PTHrP) has been identified as the major humoral factor responsible for hypercalcaemia of malignancy. ${ }^{2-6} \mathrm{~A}$ minority of patients, with extensive disease, have unmeasurable plasma PTHrP concentrations, and no evidence of activation of renal PTH receptors. parathyroidism, survival

\section{Plasma PTHrP}

- Elevated in majority of patients with hypercalcaemia of malignancy

- Assays now readily available

Although serum PTH is generally undetectable or low in patients with hypercalcaemia and malignant disease, recent studies have demonstrated that a significant proportion (4-15\%) of such patients have an elevated serum PTH, either alone or in combination with a high plasma PTHrP. ${ }^{5-8}$ In the majority of these patients, parathyroidectomy confirmed a diagnosis of hyperparathyroidism and was followed by remission of the hypercalcaemia.

The prognosis of patients with hypercalcaemia and malignancy is generally poor. Ralston $e t$ al found a median survival of 35 days, which was unaffected by hypocalcaemic therapy but which increased to 135 days following anti-tumour therapy. ${ }^{1}$ It is thought that treatment of the hypercalcaemia is not always optimal, ${ }^{9}$ and this may lead to unnecessary morbidity. In contrast, the prognosis of patients with hyperparathyroidism and with no evidence of malignancy is extremely good. ${ }^{10}$ Here we compare survival in patients with malignant disease in whom hypercalcaemia was due to hyperparathyroidism or malignancy and assess the value of assays for PTH and PTHrP in predicting survival in hypercalcaemic patients with malignant disease.

\section{Patients}

Forty-seven patients with solid tumours were identified from 121 consecutive unselected patients with hypercalcaemia (defined as a serum adjusted calcium concentration greater than $2.65 \mathrm{mmol} / \mathrm{l}$; adjusted calcium = measured calcium $+0.02[40-$ albumin $(\mathrm{g} / \mathrm{l})]$ ), who had biochemical profiles (including serum calcium) measured in the pathology department of a district general hospital between October 1990 and May 1991.6 These 47 patients were divided into two groups, according to the serum PTH measured at the time of presentation with hypercalcaemia.

GROUP 1

This comprised seven patients in whom hyperparathyroidism had been diagnosed on the basis of an elevated serum PTH $(>4.0 \mathrm{pmol} / \mathrm{l})$ 
in the presence of hypercalcaemia. In three patients a parathyroid adenoma was confirmed surgically, with subsequent normalisation of the serum calcium. In no case was hyperparathyroidism diagnosed prior to presentation with malignancy. Primary sites of malignancies were adenocarcinoma of the breast (two patients) and one patient each with bronchial squamous-cell carcinoma with rectal adenocarcinoma, bronchus with myeloma, carcinoma of the stomach, carcinoma of the colon, and leiomyosarcoma.

\section{GROUP 2}

This comprised 40 patients with a suppressed or low-normal serum PTH, all of whom were considered to have hypercalcaemia of malignancy. Primary sites of malignancy were the bronchus (14), breast (five), gynaecological (five), two each with carcinoma of the kidney, prostate, pharynx or larynx, pancreas, and skin, one each with carcinoma of the colon and synovium and four unknown. Plasma PTHrP was elevated $(>0.5 \mathrm{pmol} / \mathrm{l})$ in 35 of these patients.

Hypercalcaemia was treated with rehydration and intravenous bisphosphonates as required. Five patients received anti-tumour therapy after the onset of hypercalcaemia. One patient from Group 1 underwent colectomy; while two patients from Group 2 underwent surgery (one hysterectomy ${ }^{11}$ and one amputation, both with resolution of hypercalcaemia) and two received radiotherapy.

\section{Methods}

PTHrP(1-86) was assayed in plasma by an in-house immunoradiometric method, as previously described. ${ }^{3}$ The detection limit of this assay was $0.5 \mathrm{pmol} / \mathrm{l}$, and levels in normocalcaemic controls are undetectable. PTH(1-84) was measured in serum using the ' $\mathrm{N}$-tact' immunoradiometric assay (Incstar, Wokingham UK). The reference range for this assay in normocalcaemic controls is $0.9-4.0 \mathrm{pmol} / 1$. All specimens for assay of PTH and PTHrP were collected prior to treatment of patients with bisphosphonates. ${ }^{12}$

The dates when malignancy and hypercalcaemia were first diagnosed were obtained from patients' notes. Because of this retrospective dating of the onset of hypercalcaemia and the variety of clinicians (both hospital and community-based) in overall charge of patient care, accurate staging of disease at the time of onset of hypercalcaemia was rarely available; however, the presence or absence of extralymphatic metastatic disease as indicated by imaging techniques or at surgery was noted. Dates of death were obtained from hospital, general practitioner or Family Health Services Authority records.

Differences between groups in the mean age at diagnosis, and in serum PTH and plasma PTHrP at the onset of hypercalcaemia, were compared using Student's $t$-test. Differences in survival at 100 days and at one year from both diagnosis of malignancy and the onset of hypercalcaemia were compared using Fisher's exact probability test. ${ }^{13}$ In addition, differences in median survival from diagnosis and from the development of hypercalcaemia were compared by the Mann-Whitney test, using the MINITAB statistical program (Minitab Inc, Pennsylvania, USA).

\section{Results}

Patient characteristics are shown in the table. No significant difference was seen between groups 1 and 2 in the mean age at diagnosis of malignancy, although patients in group 1 tended to be older. Malignancy was diagnosed before the onset of hypercalcaemia in three $(43 \%)$ patients in group 1 , and $29(73 \%)$ in group 2 (no statistically significant difference). Extra-lymphatic metastatic disease was known to be present in $23(57.5 \%$ ) patients from group 2 at the time of onset of hypercalcaemia, compared to none in group $1(p=0.011)$. After investigation, four patients $(57.1 \%)$ in group 1 and five $(12.5 \%)$ in group 2 had no evidence of extra-lymphatic metastases; data were not available in three patients $(42.9 \%)$ from group 1 and $12(30 \%)$ from group 2 . The mean serum PTH was 8.97 (SEM 2.01) pmol/1 in group 1, and 0.81 (SEM 0.08) $\mathrm{pmol} / 1$ in group 2 $(\mathrm{p}<0.01)$. Mean PTHrP concentrations were 0.83 (SEM 0.38) and 4.87 (SEM 0.70) pmol/1 in groups 1 and 2 , respectively $(p<0.001)$.

Following the diagnosis of malignancy, $6 / 7$ $(86 \%)$ patients in group 1 survived for one

Table Biochemistry at onset of hypercalcaemia, mean age at death, and median survival following the diagnosis of malignancy and of hypercalcaemia

\begin{tabular}{|c|c|c|c|c|c|c|c|c|}
\hline & $\begin{array}{l}\text { Number of } \\
\text { patients }\end{array}$ & $\begin{array}{l}\text { Number with } \\
\text { known metastases }\end{array}$ & $\begin{array}{l}\text { Calcium } \\
(\mathrm{mmol} / \mathrm{l})\end{array}$ & $\begin{array}{c}\text { PTH } \\
(p m o l / l)\end{array}$ & $\begin{array}{l}\text { PTHrP } \\
(\mathrm{pmol} / \mathrm{l})\end{array}$ & $\begin{array}{l}\text { Age at death } \\
\text { (years) }\end{array}$ & $\frac{\text { Survival (days) }}{\text { malignancy }}$ & $\frac{\text { from diagnosis of }}{\text { hypercalcaemia }}$ \\
\hline $\begin{array}{l}\text { Group } 1 \text { PTH ele } \\
\text { Mean (SEM) } \\
\text { Median (range) }\end{array}$ & 7 & $0(0 \%)^{\star}$ & $2.88(0.05)^{\star}$ & $9.0(2.0)^{\star}$ & $0.8(0.4)^{\star}$ & $77.8(4.0)$ & $949(26-3652)$ & $817(9->1213)^{\star}$ \\
\hline $\begin{array}{l}\text { Group } 2 \text { PTH su } \\
\text { Bronchus } \\
\text { Breast } \\
\text { Other tumours } \\
\text { Mean (SEM) } \\
\text { Median (range) }\end{array}$ & $\begin{array}{r}\text { ssed } \\
14 \\
5 \\
21 \\
40\end{array}$ & $\begin{array}{c}5(36 \%) \\
5(100 \%) \\
13(62 \%) \\
23(57.5 \%)\end{array}$ & $\begin{array}{l}3.23(0.09) \\
3.00(0.10) \\
3.15(0.11) \\
3.16(0.07)\end{array}$ & $\begin{array}{l}0.8(0.1) \\
0.8(0.1) \\
0.8(0.1) \\
0.8(0.1)\end{array}$ & $\begin{array}{l}7.1(1.3) \\
2.8(1.1) \\
3.8(0.9) \\
4.9(0.7)\end{array}$ & $\begin{array}{l}71.1(2.8) \\
66.0(4.8) \\
70.4(2.3) \\
70.1(1.7)\end{array}$ & $\begin{aligned} 82 & (6-221) \\
2453 & (1459-3209) \\
307 & (19-6965) \\
183 & (6-6965)\end{aligned}$ & $\begin{array}{l}24(2-221) \\
33(25-70) \\
44(8->1107) \\
33(2->1107)\end{array}$ \\
\hline
\end{tabular}

$>$ ' indicates one or more patients remained alive on review; ${ }^{\star} \mathrm{p}<0.05$ vs Group 2; other comparisons not significant. 


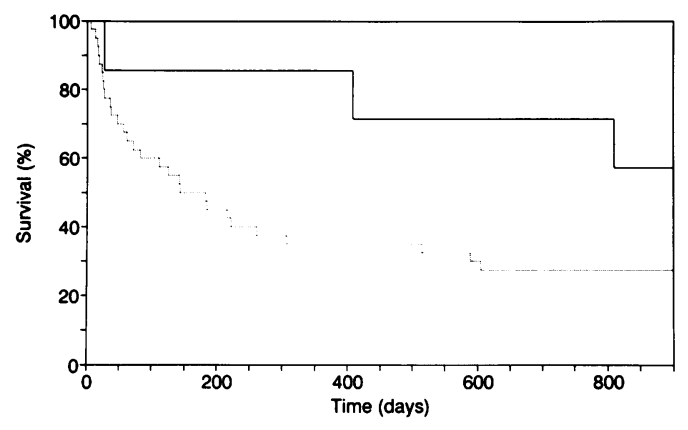

Figure 1 Survival from the diagnosis of malignancy. Group 1;....... Group 2

year, compared to $16 / 40(40 \%)$ in group 2 $(p=0.03$; Fisher's exact probability (figure 1 ). After the onset of hypercalcaemia, $6 / 7$ patients $(86 \%)$ from group 1 and $9 / 40(22 \%)$ from group 2 survived for 100 days $(p=0.0009)$, and $5 / 7(71 \%)$ from group 1 and $1 / 40(2 \%)$ from group 2 remained alive after one year $(p=0.0002)$ (figure 2 ). The single survivor in group 2 had a hysterectomy with complete resection of her tumour and subsequent normalisation of calcium, PTH and PTHrP levels. ${ }^{11}$ Median survival following the detection of hypercalcaemia was 817 days in group 1 compared to 33 days in group 2 (95\% confidence limits 85-923 days for difference between medians; $p=0.007$, Mann-Whitney test). Unlike survival from diagnosis, survival from the onset of hypercalcaemia in group 2 was not dependent on the site of the primary malignancy. None of the survivors in group 1 received anti-tumour therapy after the detection of hypercalcaemia.

Four patients with an elevated PTH (group 1) also had detectable plasma concentrations of PTHrP $(>0.5 \mathrm{pmol} / \mathrm{l})$. In one patient with myeloma and bronchial carcinoma, plasma PTHrP was markedly elevated ( $3.0 \mathrm{pmol} / \mathrm{l})$, suggesting coexistent hypercalcaemia of malignancy. Death occurred nine days after the development of hypercalcaemia. Plasma PTHrP was less than $1 \mathrm{pmol} / 1$ in the remaining three patients; the minimum survival from the onset of hypercalcaemia in these patients was 102 days. The patient with dual bronchial (squamous-cell) and rectal malignancies (PTH 5.9 pmol/1, PTHrP 0.94 pmol/1) survived for 817 days, despite the presence of unresectable hilar lymph node metastases from her bronchial carcinoma at the time this was diagnosed.

Within group 2, there was no difference in median survival from the onset of hypercalcaemia between those in whom plasma PTHrP was increased (34 days; range 2-1107) and those in whom it was undetectable (26 days; range $10-87$ ). In the 31 patients in whom plasma PTHrP was increased and who received no anti-tumour treatment subsequently, there was no correlation between PTHrP concentration and the duration of survival $\left(r^{2}=0.021\right.$, $\mathrm{p}=0.44$ ) (figure 3).

Among all 47 patients with malignancy, an elevated serum PTH $(>4.0 \mathrm{pmol} / \mathrm{l})$ had a positive predictive value of $86 \%$ for survival

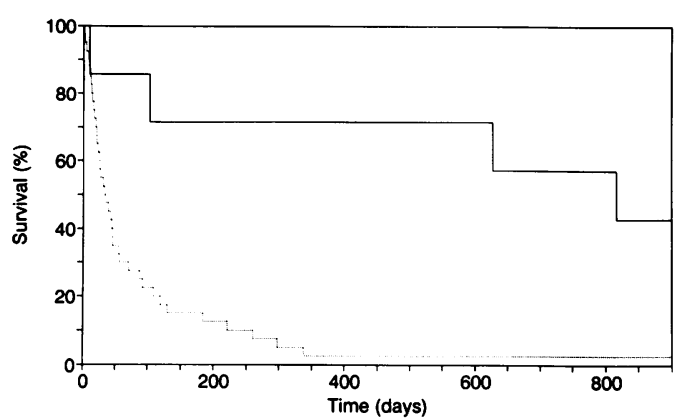

Figure 2 Survival from onset of hypercalcaemia. Group 1; ....... Group 2

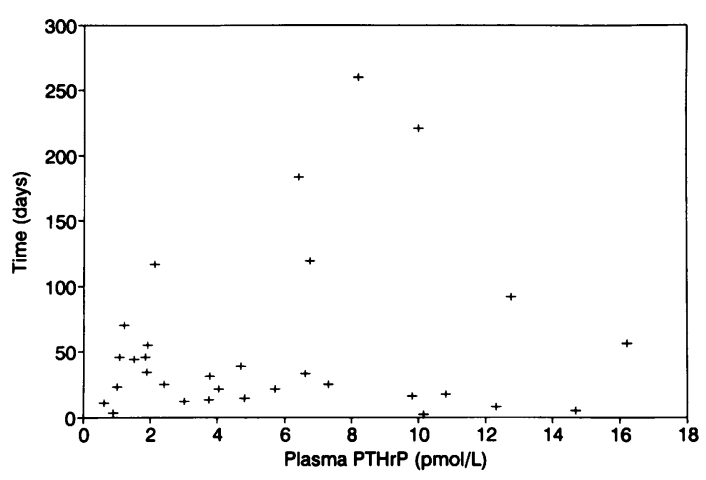

Figure 3 Duration of survival (in days from the date of PTHrP assay) in patients with hypercalcaemia of malignancy and elevated plasma PTHrP $(>0.23 \mathrm{pmol} /$ 1), compared to the plasma PTHrP concentration at the onset of hypercalcaemia. Patients who received therapy directed against their malignancy following the onset of hypercalcaemia have been excluded. $r^{2}=0.021$; not significant

greater than 100 days, and of $71 \%$ for survival greater than 1 year; negative predictive values were $77 \%$ and $97 \%$, respectively. A detectable plasma PTHrP $(>0.5 \mathrm{pmol} / \mathrm{l})$ had a positive predictive value of $69 \%$ for death within 100 days and $92 \%$ for death within one year.

\section{Discussion}

Solid malignancies and hyperparathyroidism are both common causes of hypercalcaemia, and together account for approximately $85 \%$ of cases in routine clinical practice. ${ }^{6}$ Hypercalcaemia of malignancy is the more frequent diagnosis among hospital in-patients, and the combination of hyperparathyroidism with malignancy is probably under-diagnosed. However, it is to be expected that malignancy and hyperparathyroidism may coexist by chance, and it has also been suggested that hyperparathyroidism may be associated with a slight increase in the incidence of malignancy. ${ }^{10}$

We found that the median survival of patients with both malignant disease and hyperparathyroidism was in excess of two years. In contrast, patients with hypercalcaemia of malignancy and a suppressed serum PTH had a median survival of approximately one month in keeping with the findings of Ralston et al. These workers found that treatment of the underlying malignancy improved median sur- 
vival, but only to 135 days. We found that survival from the time of diagnosis was longer in patients with coexistent hyperparathyroidism than in those who subsequently developed hypercalcaemia of malignancy. Although we were unable to stage patients' disease at the time of onset of hypercalcaemia, the majority of patients with hypercalcaemia of malignancy were known to have metastases distant from the site of the primary tumour. In contrast, no patient with hyperparathyroidism was known to have non-lymphatic metastases. Hypercalcaemia of malignancy is usually a late complication of malignant disease, ${ }^{14}$ while investigation of hypercalcaemia in patients with hyperparathyroidism may lead to early diagnosis of concurrent malignancy.

Malignancy is the commonest cause of hypercalcaemia in hospitalised patients, ${ }^{6}$ and a tendency (witnessed by us in this study, and also by others ${ }^{14}$ ) exists to assume that hypercalcaemia in a patient known to have malignant disease (past or present) implies hypercalcaemia of malignancy with a poor prognosis. Although rigorous investigation and treatment may be unethical in patients known to have widespread metastatic disease and a poor quality of life, failure to recognise those patients with malignancy and coexisting hyperparathyroidism (approximately $15 \%$ of those with hypercalcaemia and malignancy) ${ }^{6}$ may lead to their receiving inadequate treatment, with increased morbidity and possible increased mortality. When a search for skeletal metastases is performed, radionucleotide investigations may be misleading unless the presence of hyperparathyroidism has been recognised. ${ }^{14}$

The treatment of hypercalcaemia in patients with malignancy may be suboptimal even within a tertiary referral centre. ${ }^{9}$ Assays for plasma PTH are widely available, and involve minimal

1 Ralston SH, Gallacher SJ, Patel U, Campbell J, Boyle IT. Cancer-associated hypercalcaemia: morbidity and mor-

2 Bality. Ann Intern Med 1990; 112: 499-504. function and measurement. Clin Chem 1992; 38: 2171-83.

3 Ratcliffe WA, Norbury S, Heath DA, Ratcliffe JG. Development and validation of a two-site immunoradiometric assay for parathyrin-related protein in unextracted plasma. Clin for parathyrin-related pr.

4 Burtis WJ, Brady TG, Orloff JJ, et al. Immunochemica characterisation of circulating parathyroid hormone-related protein in patients with humoral hypercalcaemia of cancer. $N$ Engl f Med 1990; 322: 1106-12.

5 Fraser WD, Robinson J, Lawton R, et al. Clinical and laboratory studies of a new immunoradiometric assay of parathyroid hormone-related protein. Clin Chem 1993; 39: 414-9.

6 Ratcliffe WA, Hutchesson ACJ, Bundred NJ, Ratcliffe JG. Role of assays for parathyroid-hormone-related protein in investigation of hypercalcaemia. Lancet 1992; 339: 164-7.

Malignancy and concomitant hyperparathyroidism. F Surg Oncol 1988; 37: 10-2.

\section{Learning points}

- up to $15 \%$ of hypercalcaemic patients with cancer have hyperparathyroidism

- the prognosis in these patients is comparatively good

- measurement of serum PTH and plasma PTHrP should be considered in every case

patient stress. Diagnosis of hyperparathyroidism, with the associated improvement in prognosis compared to that of hypercalcaemia of malignancy, may encourage both the use of specific hypocalcaemic therapy, and further investigation and treatment of the malignancy.

It has been suggested that in patients with a past history of malignancy, the onset of hypercalcaemia merits assessment of parathyroid function before being attributed to (recurrent) malignancy. ${ }^{14}$ The same should apply to patients with active malignant disease, unless other factors (eg, known severe metastatic disease) indicate a prognosis of less than 3-6 months. Parathyroid function should be assessed prior to treatment with bisphosphonates, as this can lead to artifactual elevations in PTH concentration, even in the presence of persisting hypercalcaemia. ${ }^{12}$ The combination of malignancy and hyperparathyroidism is compatible with relatively prolonged survival. In patients with hyperparathyroidism, assay of plasma PTHrP can give further prognostic information, which may help to guide therapy.

We are grateful to all the clinicians who permitted us to study their patients. WAR is supported by the Department of Health.

8 Gallacher SJ, Fraser WD, Farquharson MA, et al. Coincidental occurrence of primary hyperparathyroidism and cancer-associated hypercalcaemia in a middle-aged man. Clin Endocrinol 1993; 38: 433-7.

9 Greaves I, Grant AJ, Heath DA, Michael J, Adu D. Hypercalcaemia: changing causes over the last 10 years. BMF 1992; 304: 1284

10 Heath DA. Primary hyperparathyroidism. Clinical presentation and factors influencing clinical management. Endocrinol Metab Clin N Am 1989; 18: 631-46.

11 Hutchesson ACJ, Dunne F, Bundred NJ, Gee H, Ratcliffe WA. Parathyroid hormone-related protein as a tumour marker in humoral hypercalcaemia associated with malignancy. Postgrad Med $\mathcal{F}$ 1993; 69: 640-2.

12 Fraser WD, Logue FC, Gallacher SJ, et al. Direct and indirect assessment of the parathyroid hormone response to pamidronate therapy in Paget's disease of bone and hypercalcaemia of malignancy. Bone Mineral 1991; 12: 113-21.

13 Strike PW. Statistical methods in laboratory medicine. Oxford: Butterworth-Heinemann, 1991.

14 Heath DA. Treatment of hypercalcaemia of malignancy. Baillière's Clin Endocrinol Metab 1990; 4: 139-45. 